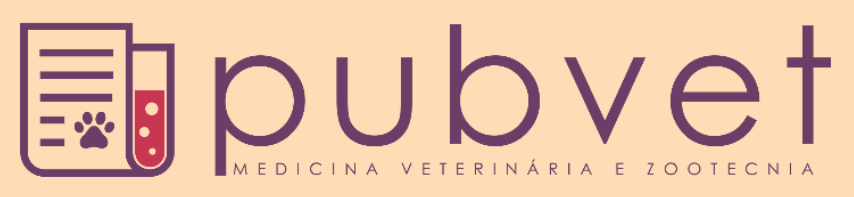

https://doi.org/10.31533/pubvet.v14n12a711.1-7

\title{
Perfil hematológico de cães e gatos destinados à castração no município de Mineiros, GO
} \author{
Ísis Assis Braga ${ }^{4} \mathbb{9}$, Karla Irigaray Nogueira Borges ${ }^{5 * 9}$ \\ ${ }^{1}$ Graduada em Medicina Veterinária pelo Centro Universitário de Mineiros UNIFIMES. Mineiros-GO Brasil. \\ ${ }^{3}$ Professor Doutor da Universidade Federal de Goiás, UFG. Jataí-GO, Brasil. \\ ${ }^{4}$ Professora Doutora do Centro Universitário de Mineiros UNIFIMES. Mineiros-GO Brasil. \\ ${ }^{5}$ Professora Especialista do Centro Universitário de Mineiros UNIFIMES. Mineiros-GO Brasil. \\ *Autora para correspondência, E-mail: biolabvet.karla@gmail.com
}

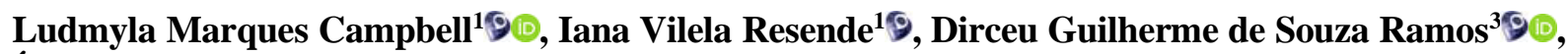

Resumo. Atualmente a cirurgia de castração é considerada um grande pilar para o controle da superpopulação de animais de companhia. Tal cirurgia se faz necessária para diminuir a incidência de abandono, a propagação de doenças, em especial as zoonoses, os acidentes de trânsito envolvendo animais, problemas no aparelho reprodutivo, dentre outras questões. Este trabalho teve como objetivo avaliar o perfil hematológico de cães e gatos inscritos no projeto de castração do município de Mineiros, GO e demonstrar as possíveis razões para cada alteração. As características encontradas em maiores proporções foram desvios à esquerda pelos neutrófilos $(31,39 \%)$, a presença de eosinofilia $(33,72 \%)$, trombocitopenia $(24,42 \%)$ e hiperproteinemia $(22,67 \%)$. O exame pré-cirúrgico é importante para a avaliação da saúde do animal e diagnosticar possíveis patologias que poderiam comprometer o sucesso do procedimento cirúrgico, além de possibilitar o tratamento prévios dos animais.

Palavras-chave: hemograma, orquiectomia, ovariohisterectomia, projeto de castração

\section{Hematological profile of dogs and cats destined for castration in the municipality of Mineiros, $G O$}

\begin{abstract}
Currently, castration surgery is considered a great pillar for controlling the overpopulation of pets. Such surgery is necessary to reduce the incidence of abandonment, the spread of diseases, especially zoonoses, traffic accidents involving animals, problems in the reproductive system, among other issues. This work aimed to evaluate the hematological profile of dogs and cats enrolled in the castration project in the municipality of Mineiros, GO, and to demonstrate the possible reasons for each change. The characteristics found in greater proportions were left deviations by neutrophils (31.39\%), the presence of eosinophilia (33.72\%), thrombocytopenia (24.42\%), and hyperproteinemia (22.67\%). The pre-surgical examination is important for the evaluation of the animal's health and to diagnose possible pathologies that could compromise the success of the surgical procedure, in addition to enabling the previous treatment of the animals.
\end{abstract}

Keywords: blood count, castration project, orchiectomy, ovariohysterectomy

\section{Perfil hematológico de perros y gatos destinados a la castración en el municipio de Mineiros, GO}

Resumen. Actualmente, la cirugía de castración se considera un gran pilar para controlar la sobrepoblación de animales de compañía. Dicha cirugía es necesaria para reducir la 
incidencia del abandono, la propagación de enfermedades, especialmente zoonosis, accidentes de tránsito con animales, problemas en el sistema reproductivo, entre otros. Este trabajo tuvo como objetivo evaluar el perfil hematológico de los perros y gatos inscritos en el proyecto de castración en el municipio de Mineiros, GO y demostrar las posibles razones de cada cambio. Las características encontradas en mayores proporciones fueron desviaciones dejadas por neutrófilos (31.39\%), presencia de eosinofilia (33.72\%), trombocitopenia $(24,42 \%)$ e hiperproteinemia $(22,67 \%)$. El examen prequirúrgico es importante para evaluar la salud del animal y diagnosticar posibles patologías que podrían comprometer el éxito del procedimiento quirúrgico, además de permitir el tratamiento previo de los animales.

Palabras clave: hemograma, orquiectomía, ovariohisterectomía, proyecto de castración

\section{Introdução}

O aumento populacional atual de cães e gatos no Brasil é nítido e, devido à falta de conscientização de tutores, houve também o aumento do abandono de animais nas ruas e, consequentemente, reprodução descontrolada de animais errantes. Frente a esse problema, torna-se necessário explicar à população o conceito de posse responsável e, dentro desse tema, a importância da castração (Rocha et al., 2017). Além da multiplicação rápida dos animais nas ruas, aumenta-se também a propagação de doenças, que podem ou não acometer o ser humano, o que consiste em um problema de saúde pública. Por outro lado, a castração também traz benefícios ao comportamento e bem-estar dos animais, além de auxiliar na prevenção de enfermidades nas mamas e no sistema reprodutor (Pereira et al., 2017; Silva et al., 2017).

O hemograma, apesar de ser um exame inespecífico, é capaz de detectar sinais caso haja alguma alteração no organismo e, além disso, indicar se o sistema imune está atuando de maneira adequada ou ineficiente (Soares et al., 2012). De acordo com Mathias et al. (2006), exames pré-operatórios têm grande importância, pois auxiliam a equipe cirúrgica a se antecipar a quaisquer alterações que possam ocorrer no trans operatório, além de interferirem na escolha dos anestésicos que serão utilizados em cada caso.

O objetivo deste trabalho é apresentar as alterações hematológicas encontradas em hemogramas de animais antes de serem submetidos à castração cirúrgica, na cidade de Mineiros, Goiás, discutindo suas possíveis causas.

\section{Material e métodos}

O Centro de Saúde Animal do Centro Universitário de Mineiros em parceria com o Bio Laboratório Veterinário teve a iniciativa de realizar um projeto de castração para animais do município de Mineiros, Goiás. Para que as cirurgias fossem possíveis, inicialmente esses cães e gatos foram submetidos à exames hematológicos para indicar se estavam aptos ou não para o procedimento.

No período de julho de 2017 a outubro de 2019, foram atendidos na clínica 172 animais aparentemente saudáveis, sendo 104 (60,47\%) cães e 68 (39,53\%) gatos, com objetivo de serem aceitos no projeto de castração. Todos eles foram submetidos à punção sanguínea através da veia jugular, cefálica ou safena e o sangue colhido foi acondicionado em tubos contendo EDTA e posteriormente foram encaminhados para o laboratório.

No hemograma foi utilizado o Analisador Celltac $\alpha$ MEC - Nihon Kohden, para obtenção de número de hemácias, hematócrito, concentração de hemoglobina corpuscular média (CHCM) e volume corpuscular médio (VCM). Esfregaços sanguíneos foram confeccionados e corados com o panótico rápido para a contagem diferencial de leucócitos, análise da morfologia das células e contagem estimada de plaquetas e citologia das mesmas, enquanto esfregaços de capas leucocitárias foram feitos para pesquisa de hemoparasitos e inclusões virais.

As mensurações de proteínas plasmáticas foram realizadas através do método de refratometria. Os dados obtidos foram inseridos em planilhas digitais para melhor visualização dos resultados. As porcentagens descritas, primeiramente foram feitas em relação à todos os cento e setenta e dois animais 
e posteriormente em relação à quantidade de exames da mesma espécie. Os hemogramas realizados foram interpretados seguindo os valores de referência (Jain, 1993; Meyer \& Harvey, 2004).

\section{Resultados e discussão}

O número total de animais que foram submetidos ao hemograma foi de 172 , sendo $104(60,47 \%)$ cães e 68 (39,53\%) gatos. A espécie, sexo e idade dos animais do projeto eram aleatórios e de acordo com uma lista de espera (Tabela 1).

Tabela 1. Espécie, sexo e idade de 172 animais submetidos à castração cirúrgica na cidade de Mineiros, Goiás, entre 2017 e 2019.

\begin{tabular}{|c|c|c|c|c|}
\hline \multirow{2}{*}{ Características } & \multicolumn{2}{|c|}{ Cães (n=104) } & \multicolumn{2}{|c|}{ Gatos $(n=68)$} \\
\hline & Absoluto & Porcentagem & Absoluto & Porcentagem \\
\hline \multicolumn{5}{|l|}{ Sexo } \\
\hline Macho & 90 & 86,54 & 51 & 75 \\
\hline Fêmea & 14 & 13,46 & 17 & 25 \\
\hline \multicolumn{5}{|l|}{ Idade } \\
\hline Filhote* & 10 & 9,62 & 25 & 36,76 \\
\hline Adulto & 86 & 82,69 & 30 & 44,12 \\
\hline Não Identificada & 8 & 7,69 & 13 & 19,12 \\
\hline
\end{tabular}

*Até um ano de idade

Os animais que não tiveram as idades identificadas e registradas eram provenientes de resgate (animais errantes), ou seja, as datas de nascimento eram desconhecidas.

Os valores hematológicos dos animais podem ser observados nas Tabela 2. De acordo com os valores de referência preconizados (Jain, 1993; Meyer \& Harvey, 2004), quatorze cães $(13,46 \%)$ demonstravam diminuição em número de hemácias, hemoglobina e/ou hematócrito, consistindo em anemia, de acordo com Nelson \& Couto (2015). Dentre estes, nove animais possuíam características de anisocitose e policromasia em suas hemácias, sendo sugestivo de anemia regenerativa (Meyer et al., 1995).

Tabela 2. Eritrograma de cães (n=104) e gatos (n=68) submetidos à castração cirúrgica na cidade de Mineiros, Goiás, entre 2017 e 2019.

\begin{tabular}{|c|c|c|c|c|}
\hline \multirow{3}{*}{ Parâmetro } & \multicolumn{2}{|c|}{ Cães $(n=104)$} & \multicolumn{2}{|c|}{ Gatos $(n=68)$} \\
\hline & $\%(\mathrm{n})$ & Referência* & $\%(\mathrm{n})$ & Referência* \\
\hline & [mín-máx] & & [mín-máx] & \\
\hline Hemácias $\left(x 10^{6} / \mu L\right)$ & {$[2,6-10,1]$} & $5,5-10,0$ & {$[5,3-12,6]$} & $5,0-10,0$ \\
\hline Abaixo & $9,6(10)$ & & $0(0)$ & \\
\hline Normal & $89,42(93)$ & & $77,9(53)$ & \\
\hline Acima & $0,96(1)$ & & $22,06(15)$ & \\
\hline Hemoglobina $(g / d L)$ & {$[6,1-20,5]$} & $12-18$ & {$[7,6-18]$} & $8-15$ \\
\hline Abaixo & $13,46(14)$ & & $1,47(1)$ & \\
\hline Normal & $77,88(81)$ & & $89,71(61)$ & \\
\hline Acima & $8,65(9)$ & & $8,82(6)$ & \\
\hline Hematócrito (\%) & [18-64] & $37-55$ & {$[25-55]$} & $24-45$ \\
\hline Abaixo & $13,46(14)$ & & $0(0)$ & \\
\hline Normal & $78,85(82)$ & & $95,65(63)$ & \\
\hline Acima & $7,69(8)$ & & $7,35(5)$ & \\
\hline$\overline{V C M}(f / L)$ & {$[38,2-77,1]$} & $60-77$ & {$[35,7-52]$} & $39-55$ \\
\hline Abaixo & $6,73(7)$ & & $4,41(3)$ & \\
\hline Normal & $92,31(96)$ & & $95,59(65)$ & \\
\hline Acima & $0,96(1)$ & & $0(0)$ & \\
\hline$\overline{C H C M}(\%)$ & {$[29,6-36,7]$} & $32-36$ & {$[28,8-37,9]$} & $30-36$ \\
\hline Abaixo & $10,58(11)$ & & $4,41(3)$ & \\
\hline Normal & $89,42(93)$ & & $92,65(63)$ & \\
\hline Acima & $0(0)$ & & $2,94(2)$ & \\
\hline
\end{tabular}

*Valores hematológicos de referência para espécie canina e felina (Jain, 1993; Meyer \& Harvey, 2004). 
Em um hemograma foi identificado a presença de metarrubrícitos, o que também pode indicar regeneração por hematopoiese (Nelson \& Couto, 2015). Cinco animais anêmicos possuíam hemácias com características normocíticas e normocrômicas sem presença de reticulócitos, indicando falta de resposta regenerativa (Garcia-Navarro \& Pachaly, 1994). Nos hemogramas dos felinos não foram encontradas alterações eritrocitárias.

No leucograma demonstrado na Tabela 3 foi feita a avaliação geral dos leucócitos e a contagem diferencial destes. O aumento da quantidade absoluta das células utiliza o sufixo "citose" ou "filia" (por exemplo: linfocitose e neutrofilia), ao passo que na diminuição dessas células é utilizado o sufixo "penia" (por exemplo: neutropenia), (Thrall, 2015). Na contagem geral das células de defesa, $10(9,62 \%)$ cães e $16(23,53 \%)$ gatos apresentaram leucocitose e $10(9,62 \%)$ cães e três $(4,41 \%)$ gatos demonstraram leucopenia.

Tabela 3. Leucograma de cães ( $(n=104)$ e gatos $(n=68)$ submetidos à castração cirúrgica na cidade de Mineiros, Goiás, entre 2017 e 2019.

\begin{tabular}{|c|c|c|c|c|}
\hline \multirow{3}{*}{ Parâmetro } & \multicolumn{2}{|c|}{ Cães $(n=104)$} & \multicolumn{2}{|c|}{ Gatos $(n=68)$} \\
\hline & $\%(\mathrm{n})$ & Referência & $\%(\mathrm{n})$ & Referência \\
\hline & [mín-máx] & & [mín-máx] & \\
\hline Leucócitos totais $\left(x 10^{3} / \mu L\right)$ & {$[2,1-24,4]$} & $6,0-17,0$ & {$[5,1-73,2]$} & $5,5-19,5$ \\
\hline Abaixo & $9,62(10)$ & & $4,41(3)$ & \\
\hline Normal & $80,77(84)$ & & $72,06(49)$ & \\
\hline Acima & $9,62(10)$ & & $23,53(16)$ & \\
\hline Neut. bastonetes $\left(x 10^{3} / \mu L\right)$ & {$[0-1.7]$} & $0-0,3$ & {$[0-4,2]$} & $0-0,3$ \\
\hline Abaixo & - & & - & \\
\hline Normal & $74,04(77)$ & & $60,29(41)$ & \\
\hline Acima & $25,96(27)$ & & $39,71(27)$ & \\
\hline Neut. segmentados $\left(x 10^{3} / \mu L\right)$ & {$[0,8-12,1]$} & $3 ., 0-11,5$ & {$[0,9-53,4]$} & $2,5-12,5$ \\
\hline Abaixo & $6,73(7)$ & & $7,35(5)$ & \\
\hline Normal & $92,31(96)$ & & $72,06(49)$ & \\
\hline Acima & $0,96(1)$ & & $20,59(14)$ & \\
\hline Linfócitos $\left(x 10^{3} / \mu L\right)$ & {$[0,1-13,9]$} & $1,0-4,8$ & {$[0,4-13,9]$} & $1,5-7,0$ \\
\hline Abaixo & $10,58(11)$ & & $4,41(3)$ & \\
\hline Normal & $75,0(78)$ & & $80,88(55)$ & \\
\hline Acima & $14,42(15)$ & & $14,71(10)$ & \\
\hline Monócitos $\left(x 10^{3} / \mu L\right)$ & {$[0-1,0]$} & $0,15-1,3$ & {$[0-1,4]$} & $0-0,85$ \\
\hline Abaixo & - & & - & \\
\hline Normal & $100(104)$ & & $97,06(66)$ & \\
\hline Acima & $0(0)$ & & $2,94(2)$ & \\
\hline Eosinófilos $\left(x 10^{3} / \mu L\right)$ & {$[0-7,7]$} & $0,1-1,2$ & {$[0,07-7,5]$} & $0-1,5$ \\
\hline Abaixo & $4,81(5)$ & & $0(0)$ & \\
\hline Normal & $61,54(64)$ & & $66,18(45)$ & \\
\hline Acima & $33,65(35)$ & & $33,82(23)$ & \\
\hline
\end{tabular}

*Valores hematógicos de referência para espécie canina e felina (Jain, 1993; Meyer \& Harvey, 2004).

Na contagem diferencial de leucócitos foram observadas as alterações no número das células específicas que compõe a série branca do sangue, sendo elas neutrófilos (sendo compostos de bastonetes e segmentados), eosinófilos, basófilos, monócitos e linfócitos.

Neutrofilia foi identificada em $15(8,72 \%)$ animais, sendo que esse desvio foi encontrado em apenas um $(0,96 \%)$ animal da espécie canina e em 14 (20,59\%) gatos. De acordo com Nelson \& Couto (2015), apesar do clínico normalmente associar a neutrofilia à casos de infecções bacterianas, nem todo animal com este quadro se encaixa nessa situação, sendo essa característica também presente em pacientes apresentando apenas inflamação ou neoplasias. A neutrofilia pode ser ainda fisiológica, resultante de situações de stress (notado principalmente, mas não exclusivamente, na espécie felina), pós exercícios, quadros convulsivos, parto, entre outras razões, devido à liberação dos neutrófilos marginalizados pelo aumento da epinefrina na corrente sanguínea (Meyer et al., 1995; Nelson \& Couto, 2015). 
Ainda em relação às alterações de neutrófilos, 27 (25,96\%) cães e 27 (39,71\%) gatos apresentaram desvio à esquerda em seus hemogramas, o que significa um aumento no número de bastonetes (neutrófilos jovens) na circulação. Quando o quadro inflamatório ou infeccioso é persistente, após o consumo da reserva de neutrófilos maduros (segmentados), a medula óssea inicia uma liberação de neutrófilos imaturos. Situações nas quais a quantidade de bastonetes está acima dos valores de referência, porém são inferiores à quantidade de segmentados, condizem com desvios à esquerda regenerativos. Entretanto, se a quantidade de bastonetes for superior à de segmentados, caracteriza um desvio à esquerda degenerativo, o que indica uma infecção grave com prognóstico reservado ou ruim. O desvio degenerativo pode estar associado à neutrofilia, neutropenia ou a valores normais de referência (Jericó et al., 2015; Nelson \& Couto, 2015).

Neutropenia foi encontrada no hemograma de $12(6,98 \%)$ e a ocorrência dessa alteração foi de $6,73 \%$ (7) cães e 7,35\% (5) gatos. A neutropenia pode estar relacionada à diminuição da sobrevida dessa célula na circulação, à queda ou interrupção completa da produção de neutrófilos por parte da medula óssea, ou sequestro pela reserva marginal. As causas mais comuns para essa alteração são doenças da medula óssea, uso de fármacos antineoplásicos e imunossupressores, choques endotóxicos ou anafiláticos, sepse, e outras infecções, como por exemplo leucemia viral felina, síndrome da imunodeficiência felina e parvovirose. É válido destacar que, mesmo saudáveis, felinos e cães da raça greyhound podem apresentar contagens baixas desse leucócito, podendo variar de 1800 a 2300/ $\mu \mathrm{L}$ (Jericó et al., 2015; Meyer et al., 1995; Nelson \& Couto, 2015).

Foram observadas respostas de eosinofilia em $35(33,35 \%)$ cães e $23(33,82 \%)$ gatos. A eosinofilia pode ser indicativa de parasitismo (endo e ectoparasitas), reações alérgicas, algumas gastroenterites, granuloma eosinofílico felino ou alguns exemplos de neoplasias (Garcia-Navarro \& Pachaly, 1994; Thrall, 2015). Cinco $(4,81 \%)$ cães apresentaram eosinopenia em seu hemograma. Ainda de acordo com Thrall (2015) e Nelson \& Couto (2015), alguns autores possuem valores de referência zero para eosinófilos, e por esse motivo, não consideram a existência da eosinopenia. Entretanto, Thrall (2015), Meyer et al. (1995), Garcia-Navarro \& Pachaly (1994) consideram existente a eosinopenia e têm como as principais causas o stress, atividade física e parto (através do sequestro de eosinófilos pela reserva marginal), bem como no uso de glicocorticoides, fase aguda da inflamação e hiperadrenocorticismo.

Os basófilos não foram encontrados em nenhum hemograma, o que condiz com as informações dadas por Nelson \& Couto (2015) e Thrall (2015), que consideram raro o aparecimento destas células em esfregaços. Foram encontradas monocitoses em apenas dois animais (ambos felinos - 2,94\%), sendo que essa alteração está relacionada a inflamações (principalmente, mas não somente, as crônicas), piometra, peritonites, piotórax, tuberculose, micoplasmose, infecções por alguns fungos e protozoários, e leucemias monocíticas ou mielomonocíticas. A monocitopenia não é considerada clinicamente importante, visto que, assim como na eosinopenia, alguns autores trazem o limite inferior de referência dessa célula como zero (Garcia-Navarro \& Pachaly, 1994; Meyer et al., 1995; Nelson \& Couto, 2015). Segundo Thrall (2015), monócitos ativados são sugestivos de combate à hemoparasitos, característica encontrada em hemogramas de dois $(1,92 \%)$ cães.

Linfocitose foi encontrada em 25 (14,53\%) animais, sendo $15(14,42 \%)$ cães e $10(14,71 \%)$ gatos. Esta condição pode ter como causas a indução por epinefrina (stress e ansiedade), reações após vacinação, doenças virais, infecções crônicas, doenças autoimunes, entre outras. Em contrapartida, a linfopenia se dá, principalmente, em infecções virais graves (como por exemplo a cinomose, coronavirose entérica, panleucopenia felina, leucemia viral felina, etc.), embora infecções por outros microorganismos (como tuberculose, brucelose, toxoplasmose, entre outras) também possam estimular essa resposta em menor escala. Também podem ocorrer devido a terapias com corticosteroides, hiperadrenocorticismo, algumas neoplasias, dentre outros (Garcia-Navarro \& Pachaly, 1994; Jericó et al., 2015; Meyer et al., 1995). A linfopenia foi identificada em $14(8,14 \%)$ hemogramas, sendo 11 $(10,58 \%)$ da espécie canina e três $(4,41 \%)$ da espécie felina. Cinco $(7,35 \%)$ felinos apresentaram linfócitos reativos, o que também pode indicar reações pós-vacinais e períodos de recuperação após infecções (Thrall, 2015).

Na plaquetometria, foram observadas nove $(5,23 \%)$ animais com trombocitose, sendo cinco $(4,81 \%)$ caninos e quatro $(5,88 \%)$ felinos. Trombocitopenia foi identificada em $42(24,42 \%)$ animais, sendo 34 
$(32,69 \%)$ em cães e oito $(11,76 \%)$ em gatos. A avaliação qualitativa das plaquetas revelou que 46 $(26,74 \%)$ hemogramas apresentaram agregados plaquetários, sendo $18(17,31 \%)$ caninos e $28(41,18 \%)$ felinos e $31(18,02 \%)$ exames com presença de macroplaquetas, sendo todos eles da espécie felina $(45,59 \%)$.

De acordo com Thrall (2015), a trombocitopenia pode aparecer em decorrência de formação de agregados plaquetários, algumas infecções (por exemplo: erliquiose, babesiose, panleucopenia e peritonite infecciosa felina), doenças autoimunes, doenças renais (por interferência da produção da trombopoietina), algumas neoplasias de medula óssea, entre outros. Em contrapartida, a trombocitose pode ocorrer em inflamações, estímulos inespecíficos dos precursores durante a anemia, proliferação por neoplasias etc.

A agregação plaquetária é algo que comumente ocorre devido à colheita de sangue inadequada, sendo que a agregação ocorre com maior frequência em sangue de felinos, podendo, algumas vezes, se manifestar como uma pseudotrombocitopenia (Nelson \& Couto, 2015). As macroplaquetas são liberadas para a circulação quando há uma grande demanda pelo corpo, entretanto ocorrem com frequência em felinos saudáveis (Reagan et al., 1999).

Em apenas um hemograma canino foi identificada a presença de mórulas de Ehrlichia canis. Tais inclusões podem ser encontradas através do esfregaço sanguíneo no citoplasma de monócitos, macrófagos teciduais ou linfócitos, embora esse teste tenha uma baixa sensibilidade (Megid et al., 2016).

As proteínas plasmáticas são compostas de albumina e globulinas e para melhor analisá-las se faz necessário uma análise bioquímica. A hiperproteinemia pode indicar desidratação, inflamações, infecções ou até mesmo algumas neoplasias (Nelson \& Couto, 2015). Já a hipoproteinemia pode se dar devido à deficiência nutricional, hemorragia, hemodiluição, nefropatias, enteropatias, dentre outras causas (Matos \& Matos, 1988; Nelson \& Couto, 2015). Neste trabalho foram observadas $39(22,67 \%)$ hiperproteinemias, $32(30,77 \%)$ em cães e sete $(10,29 \%)$ em gatos e 10 hipoproteinemias $(5,81 \%)$, sendo oito $(7,69 \%)$ em cães e duas $(2,94 \%)$ em gatos.

Foram encontrados dois $(1,18 \%)$ hemogramas com características de hemólise, sendo ambos $(1,92 \%)$ em cães. A hemólise pode ocorrer principalmente devido à erros na colheita sanguínea, armazenamento inadequado da amostra, homogeneização violenta, calor e doenças imunomediadas (Morais et al., 2018; Nelson \& Couto, 2015). Duas $(1,16 \%)$ amostras lipêmicas foram identificadas, sendo ambas $(1,92 \%)$ em cães. Essa característica se dá predominantemente devido à falta do jejum antes da colheita do sangue (Freitas et al., 2018).

Um $(0,58 \%)$ hemograma tinha característica de icterícia e este pertencia a espécie felina $(1,47 \%)$. O plasma ictérico ocorre devido à dificuldade de excreção de bilirrubina pelo organismo e tal característica pode ocorrer devido à hepatopatias, hemólise, distúrbios na metabolização da bilirrubina (Freitas et al., 2018; Nelson \& Couto, 2015).

\section{Conclusão}

Dentre todos os hemogramas analisados, nota-se que as características mais comuns foram os desvios à esquerda pelos neutrófilos, a presença de eosinofilia, trombocitopenia e hiperproteinemia. É importante salientar que, sempre que possível, o clínico deve tratar as causas bases destes problemas antes de entrar com o paciente para cirurgia, diminuindo assim as possibilidades de intercorrências no trans e pós-operatório.

\section{Referências bibliográficas}

Freitas, A. V., Freitas, M. V., Oliveira, C. G. A., Oliveira, W., Paula Kashima, Y. M., \& Barreto, J. G. (2018). Estudo da variabilidade de bilirrubina total e direta expostas à luz ambiente. Acta Biomedica Brasiliensia, 9(3), 72-79.

Garcia-Navarro, C. E., \& Pachaly, J. R. (1994). Manual de hematologia veterinária (Vol. 1). Varela.

Jain, N. C. (1993). Comparative hematology of common domestic animals. In Essentials of veterinary hematology (Vol. 1). Lea \& Febiger Philadelphia. 
Jericó, M. M., Kogika, M. M., \& Andrade Neto, J. P. (2015). Tratado de medicina interna de cães e gatos. Guanabara Koogan.

Mathias, L. A. S. T., Gozzani, J. L., Rivetti, L. A., \& Guaratini, Á. A. (2006). Exames complementares pré-operatórios: análise crítica. Revista Brasileira de Anestesiologia, 56(6), 658-668.

Matos, M. S., \& Matos, P. F. (1988). Laboratório clínico médico-veterinário. Atheneu.

Megid, J., Ribeiro, M. G., \& Paes, A. C. (2016). Doenças infecciosas em animais de produção e de companhia. Roca.

Meyer, D. J., Coles, E. H., \& Rich, L. J. (1995). Medicina de Laboratório Veterinária: diagnóstico e interpretação. Roca.

Meyer, D. J., \& Harvey, J. W. (2004). Veterinary laboratory medicine: interpretation \& diagnosis. Sauders.

Morais, L., Bosco, A. M., Baptisttiolli, L., Torrecilha, R. B. P., Valadares, T. C., Hoffmann, D. J., \& Ciarlini, P. C. (2018). Hemólise interfere na mensuração dos biomarcadores plasmáticos de estresse oxidativo em cães. Arquivo Brasileiro de Medicina Veterinária e Zootecnia, 70(3), 713-721. https://doi.org/10.1590/1678-4162-9398

Nelson, R., \& Couto, C. G. (2015). Medicina interna de pequenos animais. Elsevier Brasil.

Pereira, R. V. G., Tavares, Q. G., \& Werneck, C. L. (2017). Identificação e esterilização de cães e gatos errantes no Município de Barbacena, Minas Gerais. Muriqui: Revista de Extensão Do IF Sudeste $M G, 63$.

Reagan, W. J., Sanders, T. G., \& Nicola, D. B. (1999). Hematología veterinaria: Atlas de les especies domésticas comunes. Harcourt-Brace.

Rocha, M. F. M., Shigaeff, T., Silva, J. B. A., Gonçalves, M. F., Ortiz, T. M., \& Lopes, V. M. G. (2017). Georreferenciamento de procedimentos de esterilização cirúrgica em cães e gatos realizados no município de Praia Grande, Estado de São Paulo, Brasil no período de 2015 a 2016. Revista de Educação Continuada Em Medicina Veterinária e Zootecnia Do CRMV-SP, 15(3), 62.

Silva, T. C., Bassoli, A. G., Júnior, J. P. Q., Ferreira-Silva, J. C., Aleixo, G. A. S., \& Andrade, M. B. (2017). Castração pediátrica em cães e gatos: revisão da literatura. Medicina Veterinária (UFRPE), 9(1-4), 20-25.

Soares, B. F., Cordeiro, P. P., Sales, B. B., \& Santos, C. F. (2012). Estudo comparativo entre o hemograma humano e vetérinario. Ensaios e Ciência, 16(4).

Thrall, M. A. (2015). Hematologia e Bioquímica Clínica Veterinária. In 2. ed. Editora Roca.

\section{Histórico do artigo:}

Recebido: 26 de junho, 2020.

Aprovado: 30 de julho, 2020.

Disponível online: 2 de novembro, 2020.
Licenciamento: Este artigo é publicado na modalidade Acesso Aberto sob a licença Creative Commons Atribuição 4.0 (CC-BY 4.0), a qual permite uso irrestrito, distribuição, reprodução em qualquer meio, desde que o autor e a fonte sejam devidamente creditados. 